\title{
Communication in Developing Digital Competence of Future Professionals
}

\author{
Halyna Henseruk ${ }^{1, *}$ Mariya Boyko ${ }^{1}$ Tetiana Tsepeniuk $^{1}$ Bogdan Buyak $^{1}$ \\ Serhii Martyniuk ${ }^{1}$ \\ ${ }^{1}$ Ternopil Volodymyr Hnatiuk National Pedagogical University \\ *Corresponding author. Email: genseruk@,tnpu.edu.ua
}

\begin{abstract}
Digital transformation of education requires a higher educational institution to change its approach to the formation of professional competencies of future professionals. Development of digital competence, with Communication being one of its components, is an important aspect. The article substantiates the approaches of scholars to the interpretation of digital competence, namely its component Communication and Cooperation. The European framework and standards of digital competence of citizens and educators, which are an important tool in raising the level of digital competence of professionals, are analyzed and substantiated. The authors describe the DigComp framework of digital competence for citizens. The article describes the Digital Competence Wheel, on the basis of which in accordance with the DigComp framework, a questionnaire consisting of 24 descriptors, was developed to determine digital competence of future professionals. It has been proved that quality of the learning environment contributes to the formation of professional competencies, creates prerequisites for students' personal qualities development, provides training of a competitive specialist.
\end{abstract}

Keywords: communication, media, digital competence, digital technologies, quality.

\section{INTRODUCTION}

The 21 st century we are living in is considered the era of technology, the Internet, social media where people share their thoughts, ideas, beliefs, generate any other kind of information. Media has become an integral part of a modern person's life. We cannot imagine a day in our life without searching information in the Internet or any other sources, like books, TV etc, because information is a source for knowledge. These two elements are considered to be extremely important for a society to develop sustainably in different fields and directions. UNESCO supports the idea that "Information and means of communication (including the Internet) are integral to engaging in democratic processes, building communities, and strengthening civil society. Individuals have access to content and people to meet their fundamental needs, to communicate with others, and to improve the quality of their lives. Media and information are needed for lifelong learning, community development, economic productivity, healthcare, and all aspects of social life" $[1$, p. 7]. The development of technologies, information communication technologies in particular, contributed to the growth of the volume of information which means that anyone having access to the Internet can create and disseminate content in different forms. On the one hand, it can be beneficial for a society, as people can exchange their thoughts, ideas, knowledge, needs on different platforms, forums, blogs. On the other hand, we cannot be sure the information can be trusted as the content may be created and shared by a person having no professional expertise in the sphere of journalism. The constant flow of information makes it difficult for a recipient to "sift through and evaluate what they see, hear and read" [1, p. 8]. We cannot but agree that information influences not only our knowledge but our worldview and behaviour, which means we have to be very careful in our choice of media as sources of information, that is media consumption.

By media we mean tools that deliver users certain messages on how to use visual, audio and visual-audio means, in particular with the use of digital technologies. Today, the term "media" is used in its 
broad and narrow sense. Media in the broad meaning of the word is interpreted as a whole set of information and communication tools of various types.

Nowadays digital technologies being omnipresent in all areas of human life, are frequently used in the field of mass communication, in which under their influence transformation processes take place. They require a review of the established understanding of basic concepts of communication and the development of a new direction - media communication. At the heart of the digital transformation of mass communication we can identify several basic processes that define the main vectors, in the process of detailed consideration and analysis of which we can talk about media communication as the next form of mass communication. The most important are: digitalization, convergence, demassification, globalization. In our paper we shall focus on digitalization of mass communication.

Communication is one of the dimensions of digital competence of future professionals. It includes their knowledge and skills to communicate using digital tools, confidentiality and netiquette, exchange of information and content, knowledge of information citation rules, how to interact online to solve professional tasks, finding opportunities for selfdevelopment and improvement of their digital environment.

Professional activities in a digital society require an ethical, safe and responsible approach to the use of digital resources and technologies. Digital competence is considered by the European Commission as one of the eight key competences that are necessary for a person's full life and work. Nowadays professionals need to understand how digital technologies can help maintain their communication and collaboration. Skills of effective communication of future professionals should be formed and developed during their study at higher educational institutions. Development of techniques to encourage digital competence of future professionals, in particular Communication as one of its components, is relevant in this context.

\section{LITERATURE REVIEW}

The problem of effective use of digital technologies in the learning process is being studied by many Ukrainian and foreign scholars. Analysis of scientific works devoted to the study of components of digital competence shows the diversity of definitions of this complex concept in different methodological aspects. Thus, N.V. Morze et al have justified the willingness of future professionals to use their learning environment as a space to implement and improve their digital competencies [2]. The authors have studied the possibilities of using information technology by participants in the learning process to solve problems, in particular to communicate and cooperate. To determine the level of participants' competences in all components of digital competence, researchers suggested to prepare a short report on the topic of academic communication in high schools and present it in a digital form. O.M. Spirin considers information and communication competence of educators and interprets information and communication technologies as technologies for developing information systems and building communication networks, which usually involves psychological and pedagogical support of design, development and implementation, as well as technologies for formalizing and solving problems in certain subject areas where such systems and networks may be used [3]. S.O. Semerikov et al. substantiate technologies of e-learning and the use of cloud technologies in education, trends in the development of cloud technologies in training and retraining of future professionals $[4,5]$. V.Yu. Bykov considers the issue of competence approach and development of digital competence of participants in the learning process. The author includes, inter alia, the mobility of users' communication activities in the information space to current trends of the information society development [6]. H. Henseruk et al. study the problem of development of digital competence of future teachers in the digital learning environment [7]. According to scientists, communication is one of the important components of the digital learning environment. The digital learning environment should offer ample opportunities to facilitate communication and collaboration in a variety of forms, including feedback assessment and sharing of learning content. S. Scott considers digital competence as the ability to use digital resources and information technology, to understand and be able to critically evaluate digital resources and content, to communicate effectively [8]. The scientist identifies online communication as one of the components of digital competence. H. Soldatova considers digital competence as a complex phenomenon that determines human life in the information society and includes four types of the competence [9]. One of them is communicative competence, which includes knowledge, certain skills, motivation and responsibility required for different ways of communication (e-mail, chats, blogs, forums, social networks, etc.), which are carried out for different purposes. 
Thus, the analysis of the researches allows us to conclude about the absence of scientific papers that would elucidate the peculiarities of development of the Communication component of digital competence of future professionals.

The article is aimed at describing peculiarities of digital competence of future professionals and establishing the competencies and descriptors of the Communication component assessment. It substantiates the descriptors for assessment of the level of digital communication of future professionals and provides the findings of the conducted experiment based on these descriptors.

\subsection{Methods of research}

In our research we used a set of methods: theoretical, namely, methods of comparative analysis of scientific sources to clarify the state of the problem studied; synthesis; generalization; systematization to theoretically substantiate and develop descriptors to assess the level of digital communication; empirical, namely, survey of humanities students; analysis of research findings.

\section{RESULTS}

The European Parliament has included digital competence as one of the eight basic competences for lifelong learning. The Digital Competence Framework for Citizens, known as DigComp, was introduced in 2013 by the European Commission. The next DigComp 2.0 framework is one of the European modern strategic documents developed by the European community of countries involved in creating learning standards [10]. DigComp 2.0 includes the following levels: basic user, independent user, professional user. The development of digital technologies in various aspects of society has necessitated the version of DigComp 2.1. Updated in 2017, DigComp 2.1 is used in 21 EU countries and provides a detailed classification of digital competence, which includes 5 areas and 21 digital competences, which are necessary for all citizens, students in particular. The framework comprises the following components of digital competence:

- information and ability to work with data;

- communication and cooperation;

- creation of digital content;

- security;

- problem solving.
In our research we have considered in detail the component Collaboration and Networking.

In 2015, as a part of the ET 2020 strategy, the Joint Research Center, with the assistance of the European Commission digitalization teams, developed a framework for the digital competence of educational organizations (DigCompOrg) [11]. Based on the existing national and international systems, the DigCompOrg framework offers a comprehensive and universal framework that reflects key aspects of the systematic implementation of digital learning in educational institutions and identification of one's own progress in integration and effective use of digital technologies in the learning process. Creation of digital learning environment is considered by educational institutions as an opportunity to make the learning process open and accessible, to provide learners with high-quality education. Resources, opportunities of the learning environment determine the strategy of a higher educational institution development, its ability to compete on the market of educational services through the creation of prerequisites (opportunities) and resources (material, financial, personal, technological, organizational etc.). The quality of the learning environment (training in compliance with the requirements of the time, the availability of IT infrastructure, human resources of a higher educational institution, etc.) determine the effectiveness and efficiency of the process of training future professionals.

The learning environment in the context of professional competences aims at taking into account the interests, abilities of the subjects of the learning process; it helps to identify and maximize the individual capabilities of students, development of soft skills, self-education, teamwork, successful integration into society and professional selfrealization. The learning environment is an evolving continuum which comprises activity, management, communication and digital components that purposely influence the interaction of all participants in the learning process.

The DigCompOrg framework consists of seven thematic elements common to all education sectors. They include 15 constituent elements based on 74 descriptors. All elements are interconnected and should be considered as part of one whole. Each of these seven elements reflects different aspects of the complex process of integration and effective use of digital learning technologies. The DigCompOrg shell consists of seven thematic elements, one of which is Collaboration and Networking. A number of related sub-elements have been identified for six of the seven 
intersectoral thematic elements. An additional element is reserved for sector-specific requirements.

Table 1. Competencies of the Collaboration and Networking digital competence

\begin{tabular}{|c|c|}
\hline Competencies & Definition \\
\hline $\begin{array}{l}\text { Interaction with } \\
\text { the help of digital } \\
\text { technologies }\end{array}$ & $\begin{array}{l}\text { To interact by means of a wide } \\
\text { range of digital technologies and } \\
\text { understand which digital } \\
\text { communications are appropriate } \\
\text { for the context }\end{array}$ \\
\hline Digital exchange & $\begin{array}{l}\text { To share data, information and } \\
\text { digital content with others through } \\
\text { relevant digital technologies. To } \\
\text { act as an intermediary, know } \\
\text { practical methods of reference } \\
\text { and attribution }\end{array}$ \\
\hline $\begin{array}{l}\text { Civic engagement } \\
\text { by means of } \\
\text { digital } \\
\text { technologies }\end{array}$ & $\begin{array}{l}\text { To participate in society through } \\
\text { the use of public and private } \\
\text { digital services. To look for } \\
\text { opportunities for self-improvement } \\
\text { and implementation of active } \\
\text { citizenship by means of } \\
\text { appropriate digital technologies }\end{array}$ \\
\hline $\begin{array}{l}\text { Collaboration by } \\
\text { means of digital } \\
\text { technologies }\end{array}$ & $\begin{array}{l}\text { Use digital tools and technologies } \\
\text { for collaborative processes, as } \\
\text { well as for joint development and } \\
\text { joint creation of resources and } \\
\text { knowledge }\end{array}$ \\
\hline Netiquette & $\begin{array}{l}\text { To know the rules of conduct and } \\
\text { know-how in the use of digital } \\
\text { technologies and interaction in } \\
\text { digital environments. To adapt } \\
\text { communication strategies to the } \\
\text { target audience and take into } \\
\text { account cultural diversity and } \\
\text { generation gap in digital } \\
\text { environments }\end{array}$ \\
\hline $\begin{array}{l}\text { Digital identity } \\
\text { management }\end{array}$ & $\begin{array}{l}\text { To create and manage one or } \\
\text { more digital identities, be able to } \\
\text { protect one's own reputation, work } \\
\text { with data created through multiple } \\
\text { digital tools, environments and } \\
\text { services }\end{array}$ \\
\hline
\end{tabular}

Education in the digital era relies heavily on multidimensional communication, networking and information exchange with the internal and external knowledge ecosystem. The higher educational institution must have necessary tools, appropriate infrastructure and support systems for learning that goes beyond the institutional walls.

The thematic element Collaboration and Networking has three sub-elements and nine descriptors.

In 2017, a European Digital Competence Framework for Educators (DigCompEdu) was developed to describe aspects and assessment of digital competence of educators at the international and national levels [12]. DigCompEdu is a scientifically sound framework that helps manage policy and can be directly adapted to the implementation of regional and national tools. DigCompEdu has six areas that outline various aspects of educators' professional activity.

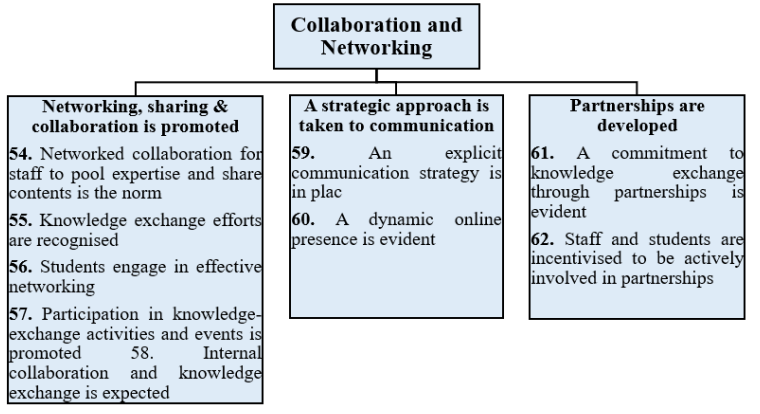

Figure 1 Thematic element Collaboration and Networking.

Within the framework of our study, the area of Professional Engagement is of great importance. It considers the digital competence of educators not only as the ability to use digital technologies in teaching, but also in professional communication with colleagues, students, parents, professional development, improvement of communication strategies and implementation of innovations in the learning process.

In the Description of digital competence of educators, digital competence is described in 5 directions. The second area - Professional Development - involves the use of digital services for professional communication, collaboration and professional development. The component 2.1 . Professional communication involves the use of digital services to improve professional communication of the educational institution with all participants in the learning process, the development of cooperation and improvement of organizational strategies of professional communication.

The fifth area Students' Digital Competence Development outlines teaching students to creatively and responsibly use digital technologies in the sphere of information data, digital communication, digital resource creation, and problem solving. The component 5.1. Information and Media Literacy involves the use of digital services to create tasks (exercises) and methods of assessment that encourage students to formulate information needs; to find data and resources in the digital learning environment; to organize, process, analyze and interpret data; to 
compare and critically evaluate the reliability of information data and the reliability of their sources.

The Center for Digital Dannelse, working on the digitalization and digital education since 2009, has developed the Digital Competence Wheel. It is based on the DigComp frameworks of digital competencies. The purpose of the Digital Competence Wheel is to identify the level of digital competence of a specialist. It provides an opportunity to identify digital competencies that need to be developed and improved.

Communication is one of four basic competence areas in the Digital Competence Wheel. Communication is a cluster of the competences of active participation, collaboration, social awareness and choice of media. Digital communication is communication through digital media.

Communication includes the ability to communicate, collaborate, interact, and participate in virtual teams and networks. It involves the use of appropriate media, tone and behavior.

The Communication area is divided into four competencies.



Figure 2 Competencies of the Communication area.

The development of digital competence of future professionals in the context of digital transformation of education is one of the main tasks in the design and development of digital learning environment in Ternopil Volodymyr Hnatiuk National Pedagogical University (TNPU).

TNPU is developing a strategy for the development of digital competence of future professionals. To implement the strategy, it is important to discover the level of digital competence of first-year students.

Within a framework of our research, a questionnaire including 24 descriptors was developed to establish the level of digital competence of humanities students in the Communication field based on the Digital Competence Wheel in accordance with the DigComp framework.

112 first-year students of the Faculty of Foreign Languages of Ternopil Volodymyr Hnatiuk National Pedagogical University took part in the survey. The questionnaire consisted of 24 questions related to the group of digital competencies in the Communication field.

\subsection{Analysis of the level of digital competencies development}

Having analyzed the survey data, we identified the level of the students' digital competence development, within the Communication component. All respondents showed Level 2 (fundamental) and Level 3 (average) grades. Data on the level of competence development are illustrated in the graphs.

The sharing of data, information and digital content with others through digital technologies descriptor appeared to be a weak point in the Active Participation competence.

Descriptors which include knowledge of digital tools for collaboration and joint creation of resources and knowledge, the ability to interact across a wide range of digital platforms appeared to be weak points in the Collaboration competence.



Figure 3 Level of the formation of the Active participation competence.

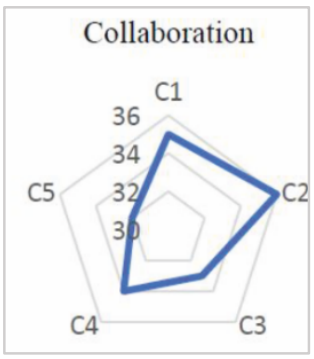

Figure 4 Level of the formation of the Collaboration competence. 
Table 2. Competencies and descriptors of the Communication field

\begin{tabular}{|c|c|c|}
\hline Competencies & Descriptor & Definition \\
\hline \multirow{5}{*}{$\begin{array}{l}\text { Active } \\
\text { participation }\end{array}$} & A1 & I understand pros and cons of the Internet in sharing messages \\
\hline & A2 & $\begin{array}{l}\text { I know professional and social media, namely Meetup, Pinterest, Flickr, LinkedIn, } \\
\text { Blogger, YouTube and Twitter }\end{array}$ \\
\hline & A3 & $\begin{array}{l}\text { I like to express my thoughts through social networks (I write in a blog, share posts } \\
\text { on social networks) }\end{array}$ \\
\hline & A4 & $\begin{array}{l}\text { I share data, information and digital content with others through relevant digital } \\
\text { technologies }\end{array}$ \\
\hline & A5 & I can create videos or articles and share them on forums \\
\hline \multirow{5}{*}{ Collaboration } & C1 & I know principles of digital collaboration \\
\hline & $\mathrm{C} 2$ & I know how to coordinate a team project \\
\hline & C3 & $\begin{array}{l}\text { I am aware of digital tools for collaboration and collaborate creation of resources } \\
\text { and knowledge }\end{array}$ \\
\hline & $\mathrm{C} 4$ & I can use digital tools in collaborate work to create resources and knowledge \\
\hline & C5 & I can interact through a wide range of digital platforms \\
\hline \multirow{5}{*}{$\begin{array}{l}\text { Social } \\
\text { awareness }\end{array}$} & O1 & $\begin{array}{l}\text { I have a predetermined position on how I will respond to an abusive comment or } \\
\text { offensive email }\end{array}$ \\
\hline & $\mathrm{O} 2$ & $\begin{array}{l}\text { I can express an opinion or feeling to a recipient using an appropriate tone when } \\
\text { writing a text }\end{array}$ \\
\hline & $\mathrm{O} 3$ & I can choose language means, image types, colors or multimedia for a recipient \\
\hline & $\mathrm{O} 4$ & I can adapt communication strategies to a specific audience \\
\hline & $\mathrm{O5}$ & I am able to consider cultural diversity and generation gap in digital environments \\
\hline \multirow{9}{*}{ Media choice } & K1 & I check the rules that should be adopted to use the Internet service \\
\hline & K2 & $\begin{array}{l}\text { I know strengths and weaknesses of communication technologies, such as } \\
\text { telephone, e-mail, chat, video conferencing, SMS }\end{array}$ \\
\hline & K3 & $\begin{array}{l}\text { I am aware of the consequences of communication through different types of } \\
\text { communication means }\end{array}$ \\
\hline & K4 & I know how to choose the best means of communication \\
\hline & K5 & $\begin{array}{l}\text { I can organize online meetings using different digital platforms, namely Zoom, } \\
\text { Meet, BigBlueButton }\end{array}$ \\
\hline & K6 & I know how to use digital boards for communication \\
\hline & K7 & $\begin{array}{l}\text { I can use digital boards for communication, namely Padlet.com, Miro.com, } \\
\text { Jamboard.com }\end{array}$ \\
\hline & K8 & I know how to use digital tools for giving feedback \\
\hline & K9 & I can use Mentimeter, Kahoot, Quizziz digital tools for giving feedback \\
\hline
\end{tabular}

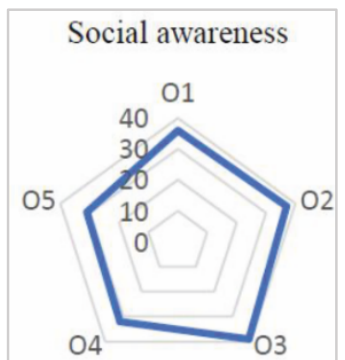

Figure 5 Level of the formation of the Social awareness competence.

Having analyzed the Social Awareness competence, we identified descriptors of the ability to adapt communication strategies to a specific audience and the ability to take into account cultural diversity and generation gaps in digital environments as being the lowest in the assessment of this level.

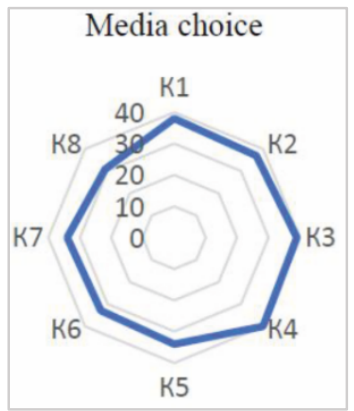

Figure 6 Level of the formation of the Media choice competence.

The Media choice competence is important in the assessment of the Communication component. Therefore, we have provided nine descriptors to assess this competence. The weak point in the assessment is 
the knowledge and ability to use digital tools for communication in the educational process.

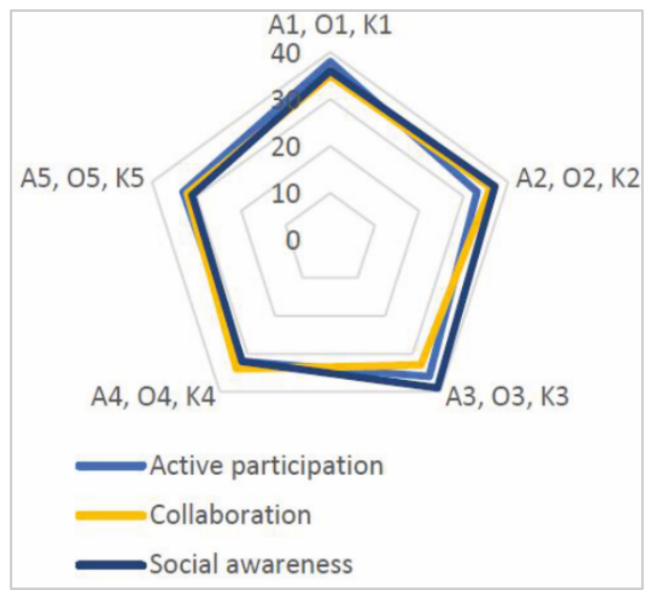

Figure 7 Correlation of competences 1-3 of the Communication component.

Considering the results of assessment of the level of formation of the first three competences, it should be noted that future professionals are partially acquainted with theoretical aspects of digital communication, relevant digital technologies for data exchange, information and digital content. However, they have a problem in implementing the practical component of digital communication. In particular, not all students can interact through a wide range of digital platforms, adapt communication strategies to a specific audience, take into account cultural diversity and generation contradictions in digital environments.

The findings show that assessment of the descriptors of the first three competencies does not differ significantly and requires the design of a strategy for the development of digital competence within the Communication component.

The next stage of the research included the design of an appropriate strategy to develop future professionals' digital competence during their study at TNPU, in particular the Communication and Cooperation component. At the meetings of the Program Councils of educational programs together with the Quality Commission of the Faculty of Foreign Languages we revised the educational programs of the first level of higher education (Bachelor's level). It was suggested to include the content module Digital Tools of Communication and Collaboration in the syllabus of the subject Modern Information Technologies in the Educational Process. Having analyzed the educational programs we singled out professionally-oriented courses in which digital technologies of media communication could be used.
Introduction of these technologies will be performed in cooperation with the lecturer of the abovementioned discipline. These are the following subjects: Methods of Teaching Foreign Languages, Introduction to Computer Linguistics, Practical Course of a Foreign Language, Introduction to CrossCultural Communication, Applied Linguistics, Digital Technologies for Translators and Basics of Media Literacy.

\section{CONCLUSIONS}

Communication is a multifaceted phenomenon. It covers various aspects of human life. Media communication as a kind of communication is distinguished by a number of its inherent specific features, the most important of them being the communicative interaction of subjects using digital technologies.

Digital transformation of mass communication requires the development of future professionals' digital competence. Considering the findings of the research, the criteria for assessing the level of future professionals' digital competence in accordance to the framework of DigComp, namely its component Communication and Cooperation, identified ways to increase the level of future professionals' digital competence. We have developed descriptors to assess the competencies of the Communication component of digital competence.

The results of the survey of first-year humanities students in TNPU showed the insufficient level of their digital competence development, namely the Communication and Cooperation component.

One of the most urgent tasks of higher education is to create such an environment in a higher educational institution that would favour the achievement of learning outcomes, provide opportunities for future professionals' self-development, stimulate their activity. After all, the learning environment functions only when it fulfills its main tasks: it forms key and subject competences, develops learners' personal qualities, creates prerequisites to train a competitive specialist.

\section{REFERENCES}

[1] S. Moeller, A. Joseph, J. Lau, T. Carbo, Towards Media and Information Literacy Indicators. Background Document of the Expert Meeting, UNESCO, Paris, 2011, 53 p.

[2] O. Kuzminska, M. Mazorchuk, N. Morze, V. Pavlenko, A. Prokhorov, Digital competency 
of the students and teachers in Ukraine, CEUR Workshop Proceedings 2104 (2018) 366-379.

[3] O. Spirin, Information and communication technologies training: criteria for internal quality assessment, Information Technologies and Learning Tools 19(5) (2010). DOI: https://doi.org/10.33407/itlt.v19i5.358

[4] O.M. Markova, S.O. Semerikov, A.M. Striuk, The cloud technologies of learning: origin, Information Technologies and Learning Tools 46(2) (2015) 29-44. DOI: https://doi.org/10.33407/itlt.v46i2.1234

[5] M.I. Striuk, S.O. Semerikov, A.M. Striuk, Mobility: a systems approach, Information Technologies and Learning Tools 49(5) (2015) 37-70.

DOI: https://doi.org/10.33407/itlt.v49i5.1263

[6] V.Yu. Bykov, O.M. Spirin, O.P. Pinchuk, Problems and tasks of the modern stage of informatization of education, in: Scientific support of education development in Ukraine: current issues of theory and practice, 2017, pp. 191-198.

[7] H. Henseruk, B. Buyak, V. Kravets, H. Tereshchuk, M. Boiko, Digital transformation of the learning environment at university, Innovative Educational Technologies, Tools and Methods for E-learning 12 (2020) 325-335. DOI: https://doi.org/10.34916/el.2020.12

[8] C. Scott, The Futures of Learning 3: What kind of pedagogies for the 21st century? UNESCO Education Research and Foresight, ERF Working Papers Series, no. 15, Paris, 2015, 21 p.

[9] L. Pietukhova, Theoretical and methodical principles of formation of informational competences of future elementary school teachers, Odessa, 2009.

[10] R. Vuorikari, Y. Punie, S. Carretero, DigComp 2.0: The Digital Competence Framework for Citizens. Update Phase 1: the Conceptual Reference Model, Publications Office of the European Union, $2016 . \quad$ DOI: https://doi.org/10.2791/11517

[11] DigCompOrg Framework, 2015. Retrieved from: https://ec.europa.eu/jrc/en/digcomporg/framewo rk.

[12] C. Redecker, Y. Punie, European Framework for the Digital Competence of Educators:
DigCompEdu, Publications Office of the European Union, $2017 . \quad$ DOI: https://doi.org/10.2760/159770 